\title{
Heparin Use in Pregnant Women Diagnosed With Thrombophilia: Obstetric Outcomes
}

\section{Júlio Rezende de Andrade ${ }^{1}$, Marina Valadão Camargos ${ }^{1}$, Mateus Figueiredo de Rezende Reis ${ }^{1}$, Ricardo Augusto Barcelos Maciel ${ }^{1}$, Tamara Teixeira Melloํㅜ, Sophia Batalha ${ }^{2}$, Hakayna Calegaro Salgado ${ }^{3}$, João Matheus de Castro Rangel ${ }^{3}$, Verônica Marques Matos ${ }^{3}$, Alexander Cangussu Silva ${ }^{3}$, Clarissa Rocha Panconi ${ }^{3}$, Larissa Milani Coutinho $^{3}$, Mariana Pinto Sirimarco ${ }^{3}$, Juliana Barroso Zimmermmann ${ }^{1,2,3^{*}}$}

${ }^{1}$ Women's Health Discipline, Medical School of Barbacena, Barbacena, Minas Gerais, Brazil; ${ }^{2}$ Maternal-Infant Department, Medical School, Federal University of Juiz de Fora, Juiz de Fora, Brazil; ${ }^{3}$ University Hospital (UH), Gynecology and Obstetrics Service-CAFederal University of Juiz de Fora, Juiz de Fora, Brazil

\begin{abstract}
Introduction: Thrombophilias are associated with venous thromboembolism. According to reports, uteroplacental thrombosis can lead to preeclampsia, intrauterine growth restriction (IUGR), placental abruption (PA) and even to fetal death. The Brazilian Ministry of Health recommends the application of heparin treatment-associated, or not, with ASA to pregnant women diagnosed with thrombophilia, based on its type. However, many studies have not been able to confirm the beneficial effects of heparin use on maternal and fetal health.

Methods: The current research is a case-control study comprising pregnant women treated at the Obstetrics Service of Federal University of Juiz de Fora and at the Medical School of Barbacena, who used heparin in the current pregnancy due to previously diagnosed thrombophilia. Current pregnancy associated with heparin use was named 'case', whereas previous pregnancy without heparin use was named 'control'. Thus, 47 cases (current pregnancy) and 32 controls were selected (1,4 cases: 1,0 control).

Results: Association between heparin and miscarriage, intrauterine fetal death and preeclampsia were analyzed. Results showed that heparin acted as protective factor against miscarriage $(O R=0.04 ; C I=0.01-0.14 ; p<0.0001)$, intrauterine fetal death $(\mathrm{OR}=0.01 ; \mathrm{CI}=0.01-0.11$; but heparin use did not reduce the frequency of preeclampsia cases $(\mathrm{OR}=0.35 ; \mathrm{CI}=0.07-1.6 ; \mathrm{p}=0.17)$.

Conclusion: Based on the current results, the early heparin application to pregnant women with thrombophilia was able to reduce the number of miscarriage, intrauterine death, but did not reduce the frequency of preeclampsia.
\end{abstract}

Keywords: Thrombophilias; Preeclampsia; Intrauterine growth restriction; Placental abruption

\section{INTRODUCTION}

Thrombophilias are associated with venous thromboembolism. According to reports, uteroplacental thrombosis can lead to preeclampsia, intrauterine growth restriction (IUGR), placental abruption (PA) and even to fetal death [1-4].

Heparin can be administered to pregnant women to treat venous thromboembolism, in thromboprophylaxis, as well as to prevent adverse obstetric effects such as preeclampsia, intrauterine growth restriction (IUGR), stillbirths and recurrent pregnancy loss. Heparin action mechanism is attributed to its anticoagulant properties, which can mitigate thrombosis in placental microvasculature. In addition, heparin is believed to have anti-inflammatory action, which results from adhesion protein blockage, from trophoblast differentiation promotion and from reduced binding between antiphospholipid autoantibodies and trophoblastic cells [5].

Unfractionated heparin (UFH) and low-molecular-weight heparin (LMWH) do not cross the placental barrier; therefore, they are the most prescribed anticoagulant drugs during pregnancy, although their prolonged use is not risk-free, since they are associated with thrombocytopenia, hemorrhage and osteoporosis. In addition, aspects such as discomfort caused by the application of these drugs, difficulty to control anticoagulation and costs with such treatments cannot be ignored. The advantages of LMWH over

Correspondence to: Dr Juliana Barroso Zimmermmann, Maternal and Child Department, School of Medicine, Federal University of Juiz de Fora, Juiz de Fora, Brazil, Tel: +5532988483345; E-mail: julianabz@uol.com.br

Received: August 28, 2019; Accepted: September 03, 2019; Published: September 10, 2019

Citation: de Andrade JR, Camargos MV, Rezende Reis MF, Maciel ABR, Mello TT, Batalha S, et al. (2019) Heparin Use in Pregnant Women Diagnosed with Thrombophilia: Obstetric Outcomes. Clinics Mother Child Health. 16:331. DOI: 10.35248/2090-7214.19.16.331

Copyright: (C) 2019 de Andrade JR, et al. This is an open-access article distributed under the terms of the Creative Commons Attribution License, which permits unrestricted use, distribution, and reproduction in any medium, provided the original author and source are credited. 
UFH are associated with average life after application, with good subcutaneous absorption and with lower incidence of thrombocytopenia [6,7]. These drugs are safe for the fetus and can be used during pregnancy both for thromboprophylaxis and thromboembolism treatment purposes [6].

Nowadays, the Brazilian Ministry of Health recommends the application of heparin treatment- associated, or not, with ASA (acetylsalicilic acid - aspirin) to pregnant women diagnosed with thrombophilia, based on its type. However, many studies have not been able to confirm the beneficial effects of heparin use on maternal and fetal health [6].

In light of the foregoing, the aim of the current study was to evaluate the frequency of unfavorable obstetric outcomes such as miscarriage, fetal death, intrauterine growth restriction and preeclampsia in pregnant women treated with heparin, by using their previous heparin-free pregnancy as control.

\section{PATIENTS AND METHODS}

\section{Patients}

The current research is a case-control study comprising pregnant women treated at the Obstetrics Service of Federal University of Juiz de Fora and at the Medical School of Barbacena, who used heparin in the current pregnancy due to previously diagnosed thrombophilia. Current pregnancy associated with heparin use was named 'case', whereas previous pregnancy without heparin use was named 'control'.

Pregnant women who did not allow their data to be included in the study, who had used heparin prior to the current pregnancy, who were pregnant for the first time and who did not follow the recommendations or the routine control defined in the service protocol, were excluded from the study. In addition, only the last pregnancy of patients presenting several previous pregnancies was taken into consideration; the other pregnancies were ignored. Thus, 47 cases (current pregnancy) and 32 controls were selected (proportion 1, 4 cases: 1, 0 control). The current research is a casecontrol study comprising pregnant women treated at the Obstetrics Service of Federal University of Juiz de Fora and at the Medical School of Barbacena, who used heparin in the current pregnancy due to previously diagnosed thrombophilia. Current pregnancy associated with heparin use was named 'case', whereas previous pregnancy without heparin use was named 'control'.

Outcomes assessed in the current study comprised intrauterine fetal death, miscarriage, preeclampsia, Hellp Syndrome, placental abruption (PA) and intrauterine growth restriction (IUGR). Patients were divided into two groups, as follows:

1- Group 1 (case) - Current pregnancy, with heparin use.

2- Group 2 (control) - Previous pregnancies, without heparin use.

\section{Methods}

Obstetric data about pregnancies, deliveries, miscarriages, previous diseases and obstetric complications, as well as results of complementary exams, mainly of thrombophilia exams, were collected from medical records.

\section{Thrombophilia screening}

All patients had been previously subjected to thrombophilia screening. The Obstetrics Service of the Medical School at Federal University of Juiz de Fora and at the Medical School of Barbacena recommend screening the following thrombophilias: protein $\mathrm{S}$ (functional activity), protein $\mathrm{C}$ (functional activity), anti-thrombin III, homocysteine measurement, as well as MTHFR, prothrombin, factor $\mathrm{V}$ (factor $\mathrm{V}$ Leiden) and PAI-1 (plasminogen-activator inhibitor) mutation. Mutations were identified based on the realtime PCR technique. The functional activity of proteins $\mathrm{S}$ and $\mathrm{C}$ was investigated through coagulometric method. Antithrombin III was investigated through chromogenic method using frozen plasma. With respect to acquired thrombophilia, APS (antiphospholipid syndrome) was investigated based on lupus anticoagulant, anticardiolipin and anti-B2 glycoprotein measurements. Anticardiolipin and anti-B2-glycoprotein screening was based on the enzyme immunoassay method, whereas lupus anticoagulant screening was based on the coagulometric method. However, APS diagnosis was based on the association between patients' clinical history and on the identification of these antibodies, as follows: 1- One or more unexplained deaths of morphologically normal fetuses observed during ultrasound examination or through direct fetus visualization after the first pregnancy trimester; 2- One or more preterm births of morphologically normal neonates, before or at the 34th pregnancy week, due to severe preeclampsia or eclampsia, or severe placental insufficiency; 3- Three or more consecutive unexplained miscarriages, before the 10th pregnancy week, without maternal hormonal or anatomical abnormalities, or maternal or paternal chromosomal causes. Thus, these antibodies were screened in case of clinical history and APS was diagnosed when at least one of them was found. All reagent results were retested on two occasions, with interval of at least 12 weeks, in order to confirm their persistence. Only positive clinical cases with persistent antibodies were taken into consideration $[7,8]$.

\section{Heparin and/or ASA use}

All thrombophilia patients were assessed based on their laboratory and clinical history. Patients with hereditary thrombophilia were treated with prophylactic heparin. Patients with MTHFR mutation and hyperhomocysteinemia were also treated with vitamin B12 and folic acid. Acquired thrombophilias were treated with prophylactic heparin dose+ASA (100 mg/day). The use of high or low molecular weight heparin was based on its availability to patients. High and low molecular weight heparin doses (5000 IU and $40 \mathrm{mg}$, respectively) were subcutaneously delivered every $12 \mathrm{~h}$. Heparin was introduced at the 6th pregnancy week, whereas ASA was introduced at the 12 th pregnancy week-whenever necessary; heparin use was interrupted 24 hours before delivery, whereas ASA use was interrupted 7 days before delivery.

\section{Statistical analysis}

All collected data were inserted in spreadsheet and processed in STATA software version 9.2. Tables composed of absolute and relative frequency were generated, and position, central tendency and dispersion measures were calculated based on the analyzed variables. The association between variables was defined based on Chi-square test, Fischer exact test, T test or Mann Whitney test, as indicated. Statistically significant differences presented p-value lower than, or equal to, 0.05 . 


\section{RESULTS}

In total, 79 patients were assessed: 47 cases and 32 controls (1,4 case: 1 control). Their mean age was $33.7 \pm 4.63$ years, mean pregnancy was $2.8 \pm 1.2$, mean delivery was $0.5 \pm 0.6$ and mean miscarriage was $1.5 \pm 1.0$. Table 1 shows clinical and epidemiological data about the assessed groups shows thrombophilia types (Figure 1).

Nine (9) out of the 79 assessed patients evolved to miscarriage in the current pregnancy (heparin-use patients). Association between miscarriage and heparin use was analyzed; results showed that heparin acted as protective factor against miscarriage, as shown in Table 2 .

Association between intrauterine fetal death and heparin use was analyzed; based on results, heparin acted as protective factor against intrauterine fetal death $(\mathrm{OR}=0.01 ; \mathrm{CI}=0.01-0.11 ; \mathrm{p}<0.0001)$, as shown in Table 3.

Association between heparin and preeclampsia was analyzed; based on results, heparin use did not reduce the frequency of preeclampsia cases. However, heparin use was associated with Hellp Syndrome $(p=0.03)$ and with IUGR/oligohydramnios $(p=0.006)$ and reduced these frequencies (Table 3).

Table 1: Epidemiological, clinical, obstetric and thrombophilia data of the assessed patients.

\begin{tabular}{|c|c|c|c|c|c|}
\hline \multirow{2}{*}{$\begin{array}{l}\text { Epidemiological, } \\
\text { clinical and obstetric } \\
\text { data }\end{array}$} & Case & Control & \multicolumn{3}{|c|}{$\mathrm{X}^{2} / \mathrm{KW}$ p value } \\
\hline & Mean + SD & Mean + SD & & & \\
\hline Pregnancies & $3.1 \pm 1.3$ & $2.40 \pm 1.1$ & 6.4 & 0 & \\
\hline Delivery & $0.61 \pm 0.7$ & $0.3 \pm 0.3$ & 5.9 & 0.01 & \\
\hline Miscarriages & $1.7 \pm 1,2$ & $1.2 \pm 0,8$ & 4.7 & 0.03 & \\
\hline Age & $33.7 \pm 4.5$ & $33.6+4.8$ & 0.03 & 0.84 & \\
\hline \multicolumn{6}{|c|}{ Previous diseases } \\
\hline \multirow[t]{2}{*}{ Hypertension } & \multicolumn{2}{|c|}{ Patients } & $\mathrm{X}^{2}$ & $\mathrm{p}$ & OR \\
\hline & Case & Control & & & \\
\hline No & 44 & 30 & 0.0006 & 1 & $0.9(0.9-1.0)$ \\
\hline Yes & 3 & 2 & & & \\
\hline Diabetes & \multicolumn{2}{|c|}{ Patients } & $\mathrm{X}^{2}$ & $\mathrm{p}$ & OR \\
\hline Gestational & 2 & 2 & 0 & 1 & $0.9(0.2-6.2)$ \\
\hline Previous (Type I or II) & 1 & 1 & & & \\
\hline
\end{tabular}

Table 2: Association between heparin use and miscarriage in pregnant women previously diagnosed with thrombophilia.

\begin{tabular}{ccccc}
\hline Miscarriage & Case & Control & p value & OR (CI 95\%) \\
\hline YES & 9 & 27 & & \\
\hline NO & 38 & 5 & $<0.001$ & $0.04(\mathrm{CI}=0.01-0.14)$ \\
\hline
\end{tabular}

Table 3: Association between heparin use and fetal growth restriction.

\begin{tabular}{lccccc}
\hline \multicolumn{7}{c}{ Heparin } & X2/KW & p value & OR $(\mathrm{CI}) 95 \%$ \\
\hline NO & YES & & & \\
\hline Fetal Growth Restriction & & & & & \\
\hline NO & 33 & 1 & & & $0.012(0 .-0.12)$ \\
\hline YES & 14 & 31 & 32.26 & 0 &
\end{tabular}

\section{DISCUSSION}

Preeclampsia, intrauterine fetal death and miscarriage were the main complications identified as pregnancies progressed. Intrauterine fetal death was most often identified in pregnant women with thrombophilia who had not previously used heparin. The association between thrombophilia and pregnancy has been increasingly investigated as the identifiable cause of adverse gestational outcomes such as placental thrombosis, severe forms of gestational hypertension, placental abruption, intrauterine growth restriction and fetal death. Any disease capable of causing placental insufficiency can be the cause of such event. 8 Pregnant women with thrombophilia who used heparin recorded the lowest frequency of fetal death $(1 / 12=8 \%)$. On the other hand, the frequency of fetal death in pregnant women with thrombophilia who did not use heparin was $88 \%$ (37/42); this outcome shows significantly reduced intrauterine fetal death in pregnant women with thrombophilia who were treated with heparin. Based on a recent study, heparin use by these patients should start as early as possible in order to optimize placentation and promote trophoblastic migration $[9,10]$. Heparin use in the current study started at the 6th pregnancy week or when the intrauterine gestational sac was identified. Thus, a successful heparin treatment may be associated with placentation process optimization.

The frequency of miscarriages reached $19 \%$ in patients treated with heparin (cases) and 84\% in patients who did not use it; based on this outcome, heparin use has significantly reduced the frequency of miscarriages. These data suggest that quality prenatal care, associated with appropriate case-specific treatment, can increase live birth rates, as well as reduce the number of miscarriages and obstetric complications [9-10]. Assumingly, heparin treatment can also be adopted in case of unexplained miscarriages, as long as the

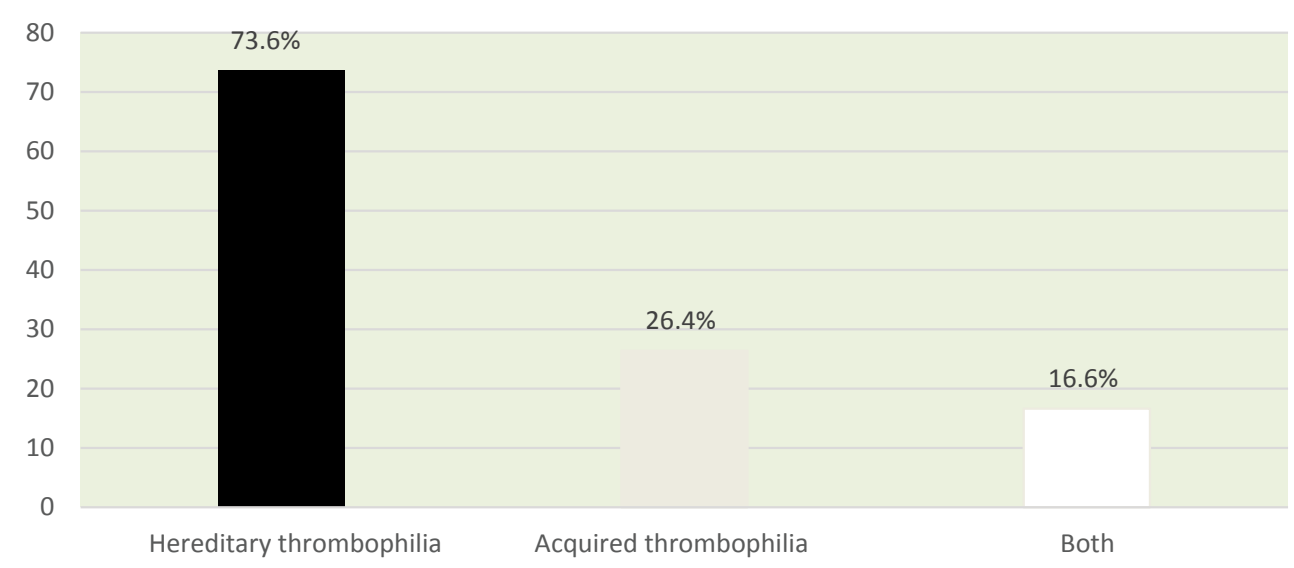

Figure 1: Type of thrombophilia. 
uterine artery presents high resistance index [11]. On the other hand, a study focused on investigating the evolution of threatened miscarriage in women treated with low molecular weight heparin (LMWH) has recorded $87.2 \%$ live births (41/47 patients) for patients who discontinued heparin use and 38.8\% (26/67 patients) for the ones who did not interrupt the LMWH treatment $(p<0.0001)$. Thus, heparin-treated patients facing threatened miscarriage were instructed by the authors of the aforementioned study to interrupt its use in order to optimize the live birth rate [12]. Another study focused on assessing 70 female patients with hereditary thrombophilia has found significantly better perinatal outcomes in women treated with heparin during pregnancy than in untreated women $(\mathrm{p}=0.006)$. Thus, despite several conflicting outcomes found in the literature, the current data support the use of heparin by pregnant patients with adverse perinatal outcome and history of thrombophilia. Assumingly, the anticoagulant properties of heparin help mitigating thrombosis in placental microvasculature and present anti-inflammatory action resulting from adhesion protein blockage, from trophoblast differentiation promotion and from reduced binding between antiphospholipid autoantibodies and trophoblastic cells [8,14-18]. According to a recent study focused on assessing pregnancy progression rate in women with acquired thrombophilia, the early-onset of heparin use has increased ongoing pregnancy rates $(81.2 \%$ vs. $60.9 \%, \mathrm{P}=0.040)$, although it did not reduce late complications [19].

Pregnant women treated, or not, with heparin in the current study did not show differences in the frequency of preeclampsia. However, other studies have associated higher frequency of hypertensive syndromes in pregnant women with thrombophilia, as well as better fetal outcomes, with heparin treatment [20-24]. The small number of patients, as well as lack of knowledge about the severity of the clinical case in this subgroup (preeclampsia), may have made such evaluation difficult. However, results were completely different when heparin was associated with Hellp Syndrome, since heparin reduced the frequency of Hellp Syndrome in pregnant women with thrombophilia. Thus, the current data are in compliance with the ones reported by Mc Laughlin et al [20], who evaluated the effects of heparin in vitro on pregnant women facing high risk of developing preeclampsia and found that serum from high-risk patients impaired endothelial cell angiogenesis and increased PlGF-1 and PlGF-2 transcription in comparison to the serum from low-risk controls. However, the exposure of this serum to LMWH has improved the angiogenic response in vitro; therefore, LMWH helps improving maternal endothelial function in pregnant women at high risk of developing preeclampsia, likely due to increased bioavailability of placental growth factors.

This mechanism in vitro could explain heparin protective action against severe preeclampsia and Hellp Syndrome [20]. However, heterogeneous studies have presented different results depending on pre-defined inclusion criteria; therefore, beneficial effects of heparin therapy on placenta-mediated diseases cannot always be properly evaluated [24]. Thus, it is essential defining whether the previous pregnancy had complications triggered by one or more aspects such as preeclampsia, placental abruption, birth of SGA neonates $[<10$ th percentile], pregnancy loss after 16 gestational weeks or two losses after 12 gestational weeks in order to better evaluate the outcomes $[23,24]$. Studies focused on investigating the use of biochemical markers to screen inefficient placentation processes are not applicable in Brazil due to their high cost; thus, clinical criteria remain widely used in the country.
Fetal growth restriction (FGR) and associated placental disorders emerge in early pregnancy, when the inadequate remodeling of maternal spiral arteries leads to persistent, high-resistance, lowflow uteroplacental circulation. Current interventions have been targeting placental ischemia-reperfusion injuries and oxidative stress associated with imbalance in angiogenic and antiangiogenic factors [25]. Hence, the current results indicate that heparin can improve fetal prognosis by reducing the likelihood of having pregnant women with thrombophilia giving birth to low growth-pattern fetuses. The current study did not evaluate different heparin types used by pregnant women. Importantly, studies conducted in vitro and in vivo have suggested that low molecular weight heparin can prevent fetal growth restriction. However, randomized controlled trials have shown inconsistent and conflicting evidences [23-27].

Aspirin was used in this study only in patients with acquired thrombophilia (antiphospholipid antibody syndrome). Such syndrome is a systemic autoimmune disease manifesting as thrombotic and/or obstetric adverse events mediated by persistent circulating antiphospholipid antibodies (aPL) detected by antibody testing (lupus anticoagulant, anticardiolipin and anti- $\beta 2$ glycoprotein I). Its main mechanism of action is the irreversible inhibition of cyclooxygenase isoenzyme activity in platelets. Thus, it blocks prostaglandin (PGI2) synthesis in endothelial cells, promoting inhibition of platelet aggregation and adhesion, allowing vasodilator effect $[28,29]$. In this study the frequency of these thrompohilias did not allow any conclusions to be drawn about this treatment association.

\section{CONCLUSION}

Based on the current results, the early heparin application to pregnant women with thrombophilia was able to reduce the number of miscarriages, intrauterine fetal death, low birth weight and Hellp syndrome cases. These results should not be extrapolated to the general population, as it was evaluated in a subgroup of pregnant women with thrombophilia. Evaluation through a clinical trial may bring new results that can be applied in medical practice. Assumingly, the large variability of results is associated with study design and with previously selected risk factors. Identifying patient subgroups (hypertensive, diabetic, thrombophilic) may be the ideal alternative to enable more efficient conclusions.

\section{REFERENCE}

1. Fonseca AG. As trombofilias hereditárias na grávida: do risco trombótico ao sucesso da gravidez. Acta Med Port 2012;25(6): 433-44.

2. Altuna D, Ceresetto J, Fassi D. Trombofilias. Sociedade Argentina de Hematologia.

3. Signor AB. Trombofilias na gestação, 2018.

4. Franco RF. Fisiologia da coagulação, anticoagulação e fibrinólise. Medicina Ribeirão Preto. 2001; 34(3): 229-237.

5. Burla M, Braga A, Coulamy LB, Oliveira T, Silva EP, Vasques F. Abortamento de repetição. Revista do Hospital Universitário Pedro Ernesto. 2015;14 (2): 34-39.

6. Barros VIPVL, Igai AMK, Andres MP, Francisco RP, Zugaib M. Resultados gestacionais e trombofilias em mulheres com história de óbito fetal de repetição. Rev Bras Ginecol Obstet. 2018;36 (2): 50-55.

7. Zimmermmann JB, Coutinho T, Duarte AMBR. Condutas em Obstetrícia para gestantes de baixo risco. Protocolo do serviço de Obstetrícia da UFJF. 
8. Oliveira MC. Trombofilia hereditária: Contribuição de factores genéticos para a predisposição de tromboembolismo venoso na população da região centro de Portugal. Dissertação apresentada à Faculdade de Ciências e Tecnologia da Universidade de Coimbra para obtenção do grau de Mestre em Biologia Animal.

9. Barros VIPVL, Igai AMK, Andres MP, Francisco RP, Zugaib M. Resultados gestacionais e trombofilias em mulheres com história de óbito fetal de repetição. Rev Bras Ginecol Obstet. 2018;36(2): 50-55.

10.Akinshina S, Makatsariya A, Bitsadze V, Khizroeva J, Khamani N. Thromboprophylaxis in pregnant women with thrombophilia and a history of thrombosis. J Perinat Med. 2018;46(8): 893-899.

11. Abou-Saif AH, Alkholy EA, Hammad RH, Hassan AH. The effect of low molecular weight heparin in recurrent pregnancy loss: changes in radial uterine artery blood flow and peripheral blood NK cell fraction. Egypt J Immunol. 2018;25(2):75-85.

12. Rottenstreich A, Amsalem H, Kleinstern G, Kalish Y. Outcomes of threatened abortions after anticoagulation treatment to prevent recurrent pregnancyloss. Reprod Biomed Online. 2017;35(4): 461-467.

13.Sokol V, Ivanišević M, Herman M, Đelmiš J. The role of low molecular weight heparin in women with hereditary thrombophilia for good perinatal outcome. Acta Clin Croat. 2016;55(2): 309-315.

14. Rey E, Kahn SR, David M, Shrier I. Thrombophilic disorders and fetal loss: A meta-analysis. Lancet. 2003;361(9361): 901-8.

15.de Jong PG, Kaandorp S, Di NM, Goddijn M, Middeldorp S. Aspirin and/or heparin for women with unexplained recurrent miscarriage with or without inherited thrombophilia. Cochrane Database Syst Rev. 2014;7:CD004734

16. de Jong PG, Goddijn M, Middeldorp S. Antithrombotic therapy for pregnancy loss. Human Reproduction Update. 2013;19 (6): 656-673.

17. Karadağ C, Yoldemir T, Karadağ SD, İnan C, Dolgun ZN, Aslanova L. Obstetric outcomes of recurrent pregnancy loss patients diagnosed with inherited thrombophilia. Ir J Med Sci. 2017;186(3): 707-713.

18. Nahas R, Saliba W, Elias A, Elias M. The Prevalence of thrombophilia in women with recurrent fetal loss and outcome of anticoagulation therapy for the prevention of miscarriages. Clin Appl Thromb Hemost. 2018;24(1): 122-128.

19. Eid MI, Abdelhafez MS, El-Refaie W, El-Zayadi AA, Samir K, Abdelrazik
$\mathrm{MM}$, et al. Timing of initiation of low-molecular-weight heparin administration in pregnant women with antiphospholipid syndrome: a randomized clinical trial of efficacy and safety. Int J Womens Health. 2019;11: 41-47.

20.McLaughlin K, Baczyk D, Potts A, Hladunewich M, Parker JD, Kingdom JC. Low molecular weight heparin improves endothelial function in pregnant women at high risk of preeclampsia. Hypertension. 2017;69(1): 180-188.

21. Wang X, Gao H. Prevention of preeclampsia in high-risk patients with low-molecular-weight heparin: A meta-analysis. J Matern Fetal Neonatal Med. 2018;20: 1-7.

22.McLaughlin K, Scholten RR, Parker JD, Ferrazzi E, Kingdom JCP. Low molecular weight heparin for the prevention of severe preeclampsia: where next? Br J Clin Pharmacol. 2018;84(4): 673-678.

23.Groom KM, McCowan LM, Mackay LK, Lee AC, Said JM, Kane SC, et al. Enoxaparin for prevention of preeclampsia and intrauterine growth restriction trial investigator group. Enoxaparin for the prevention of preeclampsia and intrauterine growth restriction in women with a history: a randomized trial. Am J Obstet Gynecol. 2017;216(3): 296. e1-296.e14.

24. Rodger MA, Gris JC, de Vries JIP, Martinelli I, Rey É, Schleussner E, et al. Low-molecular-weight heparin for placenta-mediated pregnancy complications study group. Low-molecular-weight heparin and recurrent placenta-mediated pregnancy complications: a meta-analysis of individual patient data from randomised controlled trials. Lancet. 2016; 26388(10060): 2629-2641.

25.Nawathe A, David AL. Prophylaxis and treatment of foetal growth restriction. Best Pract Res Clin Obstet Gynaecol. 2018;49: 66-78.

26. Mastrolia SA, Novack L, Thachil J, Rabinovich A, Pikovsky O, Klaitman $\mathrm{V}$, et al. LMWH in the prevention of preeclampsia and fetal growth restriction in women without thrombophilia. A systematic review and meta-analysis. Thromb Haemost. 2016;116(5): 868-878.

27. Yu YH, Shen LY, Zou H, Wang ZJ, Gong SP. Heparin for patients with growth restricted fetus: a prospective randomized controlled trial. Matern Fetal Neonatal Med. 2010;23(9): 980-7.

28.Barros VV. Tratamento da síndrome antifosfolípides na gestação. Rev Assoc Med Bras. 2002;48(2): 108-109.

29.Oliveira GMM. Antiagregantes plaquetários. Rev SOCERJ. 2001;21-27. 